\title{
Bacterial Aetiological Agents of Vended Foods in Vom, Plateau State, Nigeria
}

\author{
*Okwori AEJ ${ }^{1}$., Akele RY ${ }^{2}$., Junaid $\mathrm{SA}^{1}$., Agada GOA ${ }^{3}$., Chollom $\mathrm{SC}^{3}$., \\ Etukudoh ES ${ }^{4}$., Anejo-Okopi JA ${ }^{5}$., Adikwu T.I ${ }^{6}$ \\ ${ }^{I}$ Department of Medical Microbiology, Federal College of Veterinary and Medical Laboratory Technology, \\ Vom. ${ }^{2}$ Department of Medical Laboratory Science, College of Medicine and Health Sciences, Afe Babalola \\ University, Ado Ekiti. ${ }^{3}$ National Veterinary Research Institute, Vom. ${ }^{4}$ Federal School of Medical Laboratory \\ Technology, Jos. ${ }^{5}$ Department of Microbiology, University of Jos, Nigeria. ${ }^{6}$ Royal Infirmary Hospital,
} Edinburgh, UK

\begin{abstract}
:
Aims: Foodborne diseases are multifactorial in origin and are major cause of death worldwide. This study was aimed at detecting the presence of bacterial pathogens in already prepared vended foods in Vom.

Methodology and results: Two hundred (200) cooked food (ready-to-eat) samples were subjected to bacteriological examinations using differential, selective and enriched culture media. A total of 228 bacterial isolates were obtained. These includes Aeromonas hydrophila (3)1.5\%, Bacillus species (32)16\%, Citrobacter freundii (18)9\%, Citrobacter braekii (9) $4.5 \%$, Citrobacter youngae (1)0.5\%, Chryseomonas luteola (1)0.5\%, Enterobacter cloacae (28)14\%, Escherichia coli (14)7\%, Klebsiella pneumoniae (6)3\%, Kluyvera species (1) $0.5 \%$, Morganella morganii (3) $1.5 \%$, Providencia species (4) $2 \%$, Pseudomonas aeruginosa (5)2.5\%, Proteus mirabilis (2)1\%, Salmonella species (12)6\%, Staphylococcus aureus (34)17\%, coagulase negative Staphylococcus (49)24.5\%, Streptococcus faecalis (5) $2.5 \%$ and Vibrio hollisae (1)0.5\%, twenty one (21) samples had no bacterial growth. The identification of the Gram-negative organisms were confirmed using API 20E. These isolates were further subjected to antimicrobial sensitivity testing using the Abtex commercial disc. Most isolates were resistant to Amoxycillin, Cloxacillin, Cotrimoxazole and Erythromycin. Ciprofloxacin had about $99 \%$ activity against all the isolates.
\end{abstract}

Conclusion: The isolation of bacterial pathogens is indicative of bacterial contamination in vended foods in Vom within the period of the study.

Keywords: Bacteria-Vended Food-Vom, Nigeria

\section{Introduction}

Foodborne diseases are major cause of illness and death worldwide (Adak et al., 2002). An estimated 76 million cases of foodborne illness occur each year in the United States, costing between $\$ 6.5$ and $\$ 34.9$ billion in medical care and lost of productivity ( Mead et al., 199). In the developing world, food-borne infections leads to the deaths of many children and the resulting diarrhoea disease can have long term effects on children's growth as well as their physical and cognitive development (Guerrant et al., 1999). Foodborne illnesses continue to be a major threat to the health of people in Africa, especially vulnerable groups such as children, the elderly and people with underlying diseases such as HIV/AIDS (Mensah et al., 2012). In the industrialized world, food-borne infections cause considerable illnesses, heavily affecting health care systems (Adak et al., 2002). Bacteria are the causative agents of foodborne illness in $60 \%$ cases requiring hospitalization (Mead et al., 1999). The international impact of foodborne illness is difficult to estimate. However, due to the diarrhoeal related illnesses annually, it is suspected that food or water is a vehicle for many of these illnesses (WHO, 2002).

In the United states, incidence of foodborne illness is documented through food Net, a reporting system used by public health agencies that captures foodborne illness in over $13 \%$ of the population (IFT, 2004). Of the 10 pathogens tracked by foodnet, Salmonella, Campylobacter and Shigella are responsible for most cases of foodborne illness, Salmonella causes 31\% of food related deaths followed by Listeria (28\%), Campylobacter (5\%) and Escherichia coli 0157:H7 (35\%) (Mead et al., 1999., Mensah et al., 2012).

Contaminated food continues to cause numerous devastating outbreaks in the African Region. In Africa, a large proportion of ready-to-eat foods are sold by the informal sector, especially as street foods. The hygienic aspects of vending operations and the safety of these foods are problematic for food safety regulators. The global food crisis has worsened an already precarious food situation because when food is in short supply people are more concerned about satisfying hunger than the safety of the food (Mensah et al., 2012). The 
presence of potentially life threatening pathogens in our environment, the ability of some of them to survive and /or proliferate under refrigeration indicate the seriousness of the potential hazards with which we are faced.

This study was aimed at determining the prevalence of bacterial contaminants in foods (ready-to-eat) vended or served in Vom and its environs, Jos-South Local Government Area of Plateau State, Nigeria

\section{Sample Collection}

\section{Materials And Methods}

Two hundred samples of cooked food ready-to-eat (RTE) which includes rice, fermented milk (nono), moimoi, soup and other cooked foods which includes cassava, plantain, yam, potatoes and tuwo were collected at very low temperature from restaurants, hawkers or food vendors and residential homes in Vom and its environs by convenient sampling method as documented by Danladi et al., 2014.

The food samples were collected into a sterile universal bottle after being dished. These samples were transported to the laboratory as soon as possible and processed within 2 hours.

\section{Total Viable Count}

The modified surface drop count method of Miles and Misra as described by Ochei and Kolhatkar (2000) was used for the enumeration of each samples.

\section{Bacterial Isolation}

About $1 \mathrm{~g}$ of food sample was inoculated into $10 \mathrm{ml}$ of sterile nutrient broth, alkaline peptone water, selenite faeces (SF) and phosphate buffer saline (pH 7.2) (Fluka, Sigma, Aldrich Chemie, GmBH, Germany) and incubated for $18-24$ hours at $37^{\circ} \mathrm{C}$. The phosphate buffer saline was incubated for 21days in the refrigerator at $4^{0} \mathrm{C}$. From the nutrient broth, blood agar and MacConkey agar plates were aseptically inoculated using sterile wire loop. Cultures were incubated at $37^{\circ} \mathrm{C}$ aerobically and anaerobically for $18-24$ hours according to the method of Cheesbrough (2002). The SF broth were subcultured aseptically onto Deoxycholate agar plate (DCA)( Oxoid ,UK) and incubated at $37^{\circ} \mathrm{C}$ aerobically for 18-24 hours. Samples in alkaline peptone water were inoculated into thiosulphate citrate bile salt sucrose (TCBS) medium and incubated aerobically at $37^{\circ} \mathrm{C}$. The phosphate buffer saline (PBS) of the primary cultures were similarly subcultured onto selective media (cefsoludin irgasan novobiocin (CIN) for the isolation of Yersinia species and incubated at room temperature $\left(25^{\circ} \mathrm{C}\right)$ for $24-48$ hours (FDA/CFSAN, 2001).

\section{Bacterial Identification}

The culture plates were all read macroscopically, microscopically, enzymatically and characterized biochemically using API-20E (Sharma et al., 1990., Okwori et al., 2007).

\section{ANTIBACTERIAL SUSCEPTIBILITY TEST}

The sensitivity spectrum of each of the isolates to seven different antibiotics was determined by standardized diffusion method (NCCLS, 1995., NCCLS, 2002). The antimicrobial agents used were Ciprofloxacin $(10 \mu \mathrm{g} / \mathrm{ml})$, Tetracycline $(10 \mu \mathrm{g} / \mathrm{ml})$, Gentamycin $(10 \mu \mathrm{g} / \mathrm{ml})$, Cloxacillin $(5 \mu \mathrm{g} / \mathrm{ml})$, Erythromycin $(5 \mu \mathrm{g} / \mathrm{ml})$, Cotrimoxazole $(10 \mu \mathrm{g} / \mathrm{ml})$, and Amoxicillin $(20 \mu \mathrm{g} / \mathrm{ml})$ (Abtek biologicals Ltd, Liverpool, UK). The diameters of the zones of inhibition around each antibiotic disc were measured in millimetres.

\section{Statistical Analysis}

Descriptive statistical analysis was done using chi-square data management analysis. Differences between proportions were assessed. Statistical significance was set at 0.05 .

\section{Results}

Two hundred (200) cooked food (ready-to-eat) samples (rice, moimoi, fermented milk (nono), soup and other cooked foods) were examined for a spectrum of bacteria. A total of 228 bacterial isolates were obtained. Twenty one (21) of the food samples showed no bacterial growth.

The number of individual organism isolated and percentage occurrence is represented in Table 1. Three samples contained Aeromonas hydrophila (3)1.5\%, Bacillus species (32) 16\%, Citrobacter freundii (18) 9\%, Citrobacter braekii, (9)4.5\%, Citrobacter youngae 0.5\%, Enterobacter cloacae (28)14\%, Escherichia coli (14)7\%, Chryseomonas luteola (1)0.5\%, Klebsiella pneumonia (6)3\%, Kluyvera species (1)0.5\%, Morganella morganii (3)1.5\%, Providencia Species (4)2\%, Pseudomonas aeruginosa (5)2.5\%, Proteus mirabilis (2)1\%, Salmonella species (12)6\%, Staphylococcus aureus (34)17\%, Coagulase negative Staphylococcus (49)24.5\%, Streptococcus faecalis (5)2.5\%, Vibrio hollisae (1) $0.5 \%$. 
Each of the isolates was also subjected to antimicrobial sensitivity testing. Ciprofloxacin had a high antimicrobial activity against most of the isolates evident by a large area of inhibition elicited followed by Gentamycin (Table 3).

Table 1: Percentage spectrum of bacterial isolates

\begin{tabular}{ccc}
\hline Isolated organisms & Number of isolates & $\%$ \\
\hline Aeromonas hydrophila & 3 & 1.5 \\
Bacillus species & 32 & 16 \\
Citrobacter freundii & 18 & 9 \\
Citrobacter braekii & 9 & 4.5 \\
Chryseomonas luteola & 1 & 0.5 \\
Citrobacter youngae & 1 & 0.5 \\
Enterobacter cloacae & 28 & 14 \\
Escherichia coli & 14 & 7 \\
Klebsiella pneumonia & 6 & 3 \\
Kluyvera specie & 1 & 0.5 \\
Morganella morganii & 3 & 1.5 \\
Providencia species & 4 & 2 \\
Pseudomonas aeruginosa & 5 & 2.5 \\
Proteus mirabilis & 2 & 1 \\
Salmonella species & 12 & 6 \\
Staphylococcus aureus & 34 & 17 \\
Staphylococcus albus & 49 & 24.5 \\
Streptococcus faecalis & 5 & 2.5 \\
Vibrio hollisae & 1 & 0.5 \\
Total & 228 & 89.5 \\
\hline
\end{tabular}

Table 2: Distribution of bacterial isolates in foods screened

\begin{tabular}{|c|c|c|c|c|c|}
\hline Isolates & Rice & Moimoi & Soup & Nono & Others \\
\hline Aeromonas hydrophila & 1 & 1 & Nil & Nil & 1 \\
\hline Bacillus species & 15 & 3 & 5 & 3 & 6 \\
\hline Citrobacter freundii & 7 & 2 & 4 & 2 & 3 \\
\hline Citrobacter braekii & 2 & 1 & 2 & 1 & 3 \\
\hline Citrobacter youngae & Nil & 1 & Nil & Nil & Nil \\
\hline Enterobacter cloacae & 7 & 5 & 6 & Nil & 10 \\
\hline Escherichia coli & 4 & 2 & 5 & Nil & 3 \\
\hline Chryseomonas luteola & Nil & Nil & 1 & Nil & Nil \\
\hline Klebsiella pneumonia & 3 & Nil & 2 & Nil & 1 \\
\hline Kluyvera species & 1 & Nil & Nil & Nil & Nil \\
\hline Morganella morganii & 2 & Nil & 1 & Nil & Nil \\
\hline Providencia species & 1 & Nil & 1 & Nil & 1 \\
\hline Pseudomonas aeruginosa & Nil & 1 & 3 & Nil & Nil \\
\hline Proteus mirabilis & 1 & Nil & Nil & Nil & 1 \\
\hline Salmonella species & 2 & Nil & 7 & Nil & 3 \\
\hline Staphylococcus aureus & 5 & 5 & 3 & 17 & 4 \\
\hline Staphylococcus albus & 7 & 2 & 8 & 24 & 8 \\
\hline Streptococcus faecalis & 1 & 2 & Nil & Nil & 1 \\
\hline Vibrio hollisae & 1 & Nil & Nil & Nil & Nil \\
\hline Total & 60 & 25 & 48 & 47 & 48 \\
\hline
\end{tabular}

Table 3: Resistance pattern of bacterial isolates to antimicrobial agents.

\begin{tabular}{|c|c|c|c|c|c|c|c|}
\hline Organism & Amoxycillin & Cloxacillin & Gentamycin & Cotrimoxazole & Ciprofloxacin & Erythromycin & Tetracycline \\
\hline & $\%(*)$ & $\%(*)$ & $\%(*)$ & $\%(*)$ & $\%(*)$ & $\%(*)$ & $\%(*)$ \\
\hline Aeromonas hydrophila & $0(0)$ & $100(3)$ & $100(5)$ & $100(3)$ & $0(0)$ & $100(3)$ & $0(0)$ \\
\hline Bacillus species & $34.4(11)$ & $100(32)$ & $65.6(21)$ & $100(32)$ & $0(0)$ & $65.6(21)$ & $100(32)$ \\
\hline Citrobacter species & $50(14)$ & $100(28)$ & $25(7)$ & $89.3(25)$ & $0(0)$ & $100(28)$ & $75(21)$ \\
\hline Escherichia coli & $36(5)$ & $85.7(12)$ & $50(7)$ & $100(14)$ & $0(0)$ & $92.9(13)$ & $78.6(11)$ \\
\hline Enterobacter species & $42.9(12)$ & $85.7(24)$ & $28.6(8)$ & $100(28)$ & $0(0)$ & $85.7(24)$ & $85.6(11)$ \\
\hline Klebsiella pneumonia & $0(0)$ & $100(6)$ & $0(0)$ & $100(6)$ & $0(0)$ & $100(6)$ & $100(6)$ \\
\hline Kluyvera species & $100(1)$ & $100(1)$ & $100(1)$ & $100(1)$ & $0(0)$ & $100(1)$ & $100(1)$ \\
\hline Proteus mirabilis & $100(2)$ & $100(2)$ & $0(0)$ & $0(0)$ & $0(0)$ & $100(2)$ & $0(0)$ \\
\hline P. aeruginosa & $40(2)$ & $60(3)$ & $20(1)$ & $100(5)$ & $0(0)$ & $100(5)$ & $100(5)$ \\
\hline Salmonella species & $66.7(8)$ & $100(12)$ & $50(6)$ & $100(12)$ & $8.3(1)$ & $83.3(10)$ & $83.3(10)$ \\
\hline Staphylococcus aureus & $64.7(22)$ & $100(34)$ & $29.4(2)$ & $100(34)$ & $0(0)$ & $100(34)$ & $20.5(7)$ \\
\hline
\end{tabular}

Key:

$(*)=$ Number of resistant isolates 


\section{Discussion}

Unexpectedly, most foods still contain some micro organisms even after cooking. Consequently cooking could not be seen as sterilization as thermophilic organisms survived cooking temperature. However other sources of micro organisms in cooked meals may include, utensils, water and carrier status of some food handlers. Studies have also implicated cross contamination as a source of microbial contamination of cooked foods (Zhao et al., 2001., Beach et al., 2002).

Our study has shown high incidence of Bacillus species supporting the fact that they are aerobic spore bearers that could easily contaminate foods (Shingawa et al (1980). Its presence in various food types further buttresses the fact that this microorganism can readily be isolated from a variety of foods as previously documented by Shingawa et al (1980). Notably, Bacillus species has the ability to form heat resistant spores and thus possessing great preponderance to cause foodborne diseases. Staphylococcus aureus and coagulase negative Staphylococcus isolated in our study is similar to the findings of Bergdoll (1979) and Mohapatra et al (2002). Staphylococcus aureus normally inhabits the nose, throat, skin etc. of about $50 \%$ of healthy individuals thus increasing its chances of contaminating foods. Outbreaks of Staphylococcus aureus, Bacillus species and proteus species food poisons after eating in a restaurant have been reported by many researchers (Noah, 2009., Fry et al., 2005., Norinaga et al., 2000., Vijay et al., 2007., Lorraine et al., 2008., Yon et al., 2010., Mensah et al., 2012). Food borne intoxication is very common as documented by Mead et al (1999) and IFT (2004) owing to the ability of Staphylococcus aureus to quickly produce toxins that are heat stable causing illness even after the cells have been destroyed by cooking or reheating. Nevertheless, it remains a major cause of food borne disease because it can contaminate food products during preparation and processing (Yves et al., 2003).

This study has also shown a high incidence of Salmonella species which is in consistent with report of IFT (2004) and FDA/CFSAN (2001) implicating Salmonella as one of the leading causes of food borne illness. This is of great clinical significance since Salmonella is known to have a very low infective dose and high virulence. The presence of $E$. coli indicates faecal contamination as reported by Warburton (2000) and Josefa et al (2005). Amongst these E. coli isolated could exist the highly pathogenic E.coli 0157:H7 even though it was not searched for. The isolation of other organisms such as Aeromonas hydrophila, Chryseomonas luteola, Kluyvera species, Morganella morganii which are not regularly reported as foodborne pathogens further buttressed the reports of Mead et al (1999) that says the organisms carried by food over the few past years are gradually changing due to changes in methods of cooking, food handling and probably national or geographical variability.

Bacillus species had the highest distribution in rice thus supporting the report of Gilbert et al (1974) and Shingawa et al (1980). The presence of Salmonella species could be traced probably to the meat or vegetable in the soup, cross contamination or the handlers of the food as documented by Zhao et al (2001) and Beach et al (2002). The findings of this study has revealed the danger to which this community is exposed, thus requiring that more attention be paid to food hygiene. However, the cases studied here are not established cases of food borne disease in Vom metropolis. It is also important to state that, it is not routine that consumption of such foods so contaminated with these organisms would certainly result in a disease condition as highlighted by IFT (2004), rather, according to FDA/CFSAN (2003), outcome is dependent on the dose of organism consumed in the food, the virulence of the contaminating organism and the immune status of the consumer of such food.

Refrigeration at $4^{0} \mathrm{C}$ has been reported by Mead et al (1999) to be effective in retarding the growth of organisms in food (even though there are certain organisms that grows or multiply at $4^{\circ} \mathrm{C}$ ) thus an effective method of food storage. But with the erratic nature of power supply experienced today in Nigeria, this method is gradually going into extinction.

The relatively high level of resistance to antimicrobial agents may be reflection of misuse or abuse of these agents in the environment.

\section{References}

[1]. Adak, G. K., long, S. M. and O'Brein, S. J. C. (2002). Trends in indigenous foodborne disease and deaths. England and Wales. 1992 to 2000. GUT. 151: 832-841.

[2]. Beach, J. C., Murano, E. A. and Acuff, G. R (2002). Prevalence of Salmonella and Campylobacter in beef cattle from transport to slaughter. J. Food Prot. 65:1687- 1693.

[3]. Bergdoll, M. S. (1979). Staphylococcal Intoxication In Foodborne infections and intoxications" $2^{\text {nd }}$ ed., Ed. H. Rieman and F. L Bryan, Pp. 443 Academic press, N. Y

[4]. Cheesbrough M (2002). District Laboratory Practice in Tropical countries. Part 2. Pg. 9-13 Cambridge.

[5]. Danladi Makut Makwin, Ify Ogbonna Abigail, Joseph Okwori Ameh Eleyi and Eleojo AbubakarAisha (2014). Antibiotic susceptibility pattern of bacteria isolated from Zobo drinks sold in Keffi, Nigeria. Malaysian Journal of Microbiology, Vol 10(3)pp. 169-173

[6]. FDA/CFSAN. (2001). Draft risk assessments on the public health impact of Vibrio parahaemolyticus in raw mollus can shellfish. Center for Food Safety and Applied Nutrition, Food and Drug Admin.,College Park, Md. www.cfsan.fda.gov/ dms/vprisk.html 
[7]. FDA/CFSAN (2003). Foodborne pathogenic Microorganisms and natural toxins Handbook: The Bad Bug Book" Center for Food Safety and Applied Nutrition, Food and Drug Admin. College Park, Md. www.cfsan.fda.gov/mow/intro.ntml.

[8]. Fry A.M, Braden C.R, Griffin P.M, Hughes J.M (2005). Food borne disease. In GL Mandell et al., eds., Principles and Practice of Infectious Diseases, 6th ed., vol. 1, pp. 1286-130. Philadelphia: Elsevier Churchill Livingstone.

[9]. Gilbert, R. J., Stringer, M. F. and Peace, J. C. (1974). The survival and growth of Bacillus cereus in boiled and fried rice in relation to outbreaks of food poisoning. J.Hyg. Camb. 73: 433-444.

[10]. Guerrant, D. I., More, S. R., Lima, A. A. M., Patrick, P., Schorling, J. B. and Guerrant I, R. L. (1999). Association of early childhood diarrhea and Cryptoporidiosis with impaired fitness and cognitive function. Four- seven years later in poor urban community in Northern Brazil. Am. J. trop. Med. Hyg. 61: 707-713.

[11]. IFT (2004). Emerging Food Safety: Uses performance standards and other criteria in food inspection systems. An Authoritative Report of the Institute of Food Technologists, Chicago Organization, geneva, Switzerland.

[12]. Josefa, M. R., Phyllis, H. S., Collen, C., Patricia, M. G. and David, L. S. (2005). Epidemiology of Escherichia coli 0157:H7 outbreak, United States, 1982-2000. Emerging Infectious Disease. 11(4): 603-609.

[13]. Lorraine M, Kathryn B, Daniel B, Judith L. Isaac-Renton, David CN (2008). Identification of Bacillus cereus group species associated with food poisoning outbreaks in British Columbia and Canada. Appl Environ Microbiol 74(23): 7451 -7453.

[14]. Mead, P. S., Slutster, L., Dietz, V., McCaig, R. F., Bresec, J. S., Shapiro, C., Griffin, P.M. and Tauxe, R. V. (1999). Food related illnesses and death in the United States. Emerging Infect. Dis. 5: 607-625.

[15]. Mensah P, Mwamakamba L, Mohamed C and D Nsue-Milang (2012). Public health and food safety in the WHO African region. African Journal of food, Agriculture, Nutrition and Development. Vol. 12 No. 4 pp6317-35

[16]. Mohapatra, A.O., Rath, C. C., Dash, S. K. and Mishra, P. K. (2002). Microbiological evaluation of street food in Bhubaneswar. J. Food Sci. Techn. 39 (1): 59-61.

[17]. National Committee for Clinical Laboratory Standards (1995). Performance standards for antimicrobial disk susceptibility tests; sixth informational supplement. NCCLS Document M100-S6.National Committee for Clinical Laboratory Standards, Wayne, Pa.

[18]. National Committee for Clinical Laboratory Standards (2002). Performance standards for antimicrobial disc and dilution susceptibility tests for bacteria isolated from animals. Approved Standard 5th ed. M31-A.

[19]. Noah N. (2009). Food poisoning from raw fruit and vegetables. Introduction. Epidemiol Infect.137(3): 305-6.

[20]. Norinaga M, Asako K, Takashi M, Masato A. (2000). An outbreak of food poisoning due to egg yolk reaction-negative Staphylococcus aureus. Intern. J Food Micro 64(3): 361-366

[21]. Okwori A. E J., G.O.A. Agada., A.O. Olabode., S.E. Agina., E. S. Okpe., J. Okopi. (2007). The prevalence of pathogenic Yersinia enterocolitica among diarrhea patients in Jos, Nigeria. African Journal of Biotechnology Vol. 6 (8): 1031-1034.

[22]. Ochei J. and Kolhatkar A. (2000). Medical laboratory science, theory and practice. Pgs 11:663 - 664, 683 - 686, 689- 696, 710 - 711, 746 - 748, publisher - Tata Mc Graw - Hill Publishing Company limited Edition

[23]. Sharma, N. K., Doyle, P. W., Gerbasi, S. A. and Jessop, J. H. (1990). Identification of Yersinia species by API 20E. Journal of Clinical Microbiol. 28: 14431444.

[24]. Shinagawa, K., Kunita, N., Onaka, T. and Takemasa, N. (1980). A serotypes of Bacillus cereus isolated from cooked and raw rice responsible for food poisoning from health people. J. Food. Hyg. Soc. Japan. 21: 266.

[25]. Vijay N, Ranu A, Dev VK, Ajay KG, Lokendra S. (2007). Isolation and characterization of heat resistant enterotoxigenic Staphylococcus aureus from a food poisoning outbreak in India subcontinent. Inter J of Food Micro 117(1): 29-35.

[26]. Warburton, W. W. (2000). Methodology for screening bottled water for the presence of indicator and pathogenic bacteria. Food Microbiol 17: 3-12.

[27]. WHO (2002). Fact sheet 237: Food safety and food borne illness. World Health

[28]. Yong W, Shouyin Z, Jiyun Y, Hui Z, Zhengquan Y, Yansong S, Ling Z, Yunfeng Z, Hongbin S. (2010). An outbreak of Proteus mirabilis food poisoning associated with eating stewed pork balls in brown sauce, Beijing. Food Control 21(3): 302 - 305.

[29]. Yves L.L, Baron F, Gautier M (2003). Staphylococcus aureus and food poisoning Genet. Mol. Res. 2 (1): 63-76

[30]. Zhao, C., Ge, B., Villena, J., Sudler, R., Yeh, E., Zhao, S., White, D. G., Wagner, D. and Meng, J. (2001). Prevalence of Enterobacter species, Escherichia coli and Salmonella serovars in retailed chicken, turkey, pork and beef from the greaten Washington D. C area. Appl. Environ. Microbiol. 57(12): 5431-5436. 